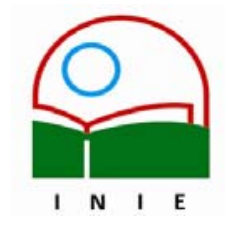

Universidad de Costa Rica

Facultad de Educación

Instituto de Investigación en Educación

ACTUALIDADES INVESTIG ATIVASEN EDUCACION

\title{
¡ABRIR LAS PUERTAS AL MUNDO DE LAS PALABRAS! CÓMO FAVORECER LA UTILIZACIÓN ADECUADA DEL AMBIENTE LETRADO EN EL NIVEL INICIAL
}

\author{
OPENING THE DOORS TO THE WORLD OF WORDS! \\ HOW TO FAVOR THE ADEQUATE USE OF BACKGROUND KNOWLEDGE AT THE \\ BEGINNING LEVEL
}

\begin{abstract}
Patricia Rojas Núñez ${ }^{1}$
Resumen: En el presente artículo se realiza una reflexión en torno a la función principal del nivel inicial y del proceso de construcción del conocimiento que realiza el niño y la niña en relación con la lectura y la escritura. Asimismo se dan a conocer algunos aspectos generales de la filosofía del Lenguaje Integral y se proponen algunas sugerencias para acercar al niño y a la niña de manera natural a la utilización del lenguaje escrito y de la lectura en las aulas preescolares.
\end{abstract}

Palabras clave: EDUCACIÓN INICIAL/ LENGUAJE INTEGRAL/ LECTURA Y ESCRITURA

Abstract: In this article there is a reflection about the main function of the initial level of knowledge and its construction process made by boys and girls on the reading and the writing process. Also, there are some general aspects of the Whole Language Philosophy, and some suggestions to attract the boy and the girl on a natural way to the use of the writing and reading languages in the pre-school classrooms.

Key words: INITIAL EDUCATION, INTEGRAL LANGUAGE, READING AND WRITING

\section{Introducción}

Los niños y niñas desde edades muy tempranas han demostrado su interés natural por la lectura y la escritura, este proceso se inicia con los primeros garabatos y dibujos que ellos y ellas realizan. Al respecto Goodman, (1997) señala que docentes e investigadores interesados en este proceso han observado cómo los infantes leían libros, revistas o cualquier otro material gráfico y, cómo éstos a su vez empleaban lápices u otros medios para representar sus significados. Desde esta perspectiva, ellos y ellas hacen uso de la lectura y escritura para aprender a leer y escribir.

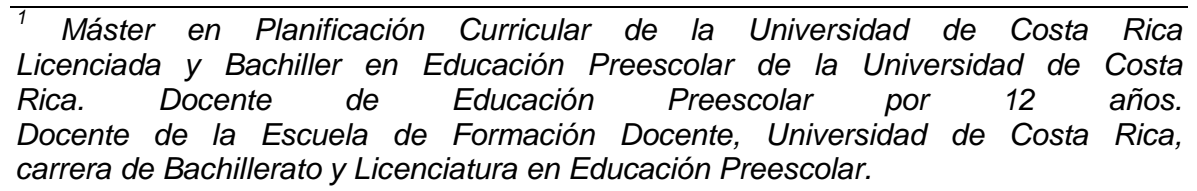

Correo electrónico: arojasn@hotmail.com

Artículo recibido: 18 de octubre, 2006

Aprobado: 4 de diciembre, 2006 
A medida que los diversos estudiosos fueron descubriendo cómo los niños y niñas formulaban hipótesis en cuanto al aprendizaje de la lectoescritura, estos han llegado a la conclusión de que ambos utilizan diversas estrategias para leer y escribir: claves semánticas (lectura de etiquetas de productos o rótulos de elementos del medio), pruebas de hipótesis, la manipulación y la exploración espontánea del lenguaje; además, en este proceso interviene la experiencia previa de cada uno con las letras (Harste et al. 1982, citado por Ruiz, 1996).

Al respecto, Ruiz (1996) señala que los niños preescolares están muy familiarizados con las letras de las calles, los letreros de comercios, las etiquetas de productos, entre otros. Goodman y Altwerger (1981) sugieren que el desarrollo de la alfabetización como proceso natural, comienza antes de la educación formal, principalmente cuando el niño y la niña comprenden que las palabras escritas comunican un mensaje que sustituye los símbolos auditivos que se emplean para identificar objetos, acciones o diversas situaciones.

Esta condición les permite que en su proceso activo de aprendizaje, construyan conocimiento sobre lectoescritura, apropiándose de los significados del lenguaje que su ambiente le brinda. En este sentido, Ruiz (1996) y ArellanoOsuna (1990) señalan que los niños y niñas que desarrollan su conocimiento sobre el lenguaje

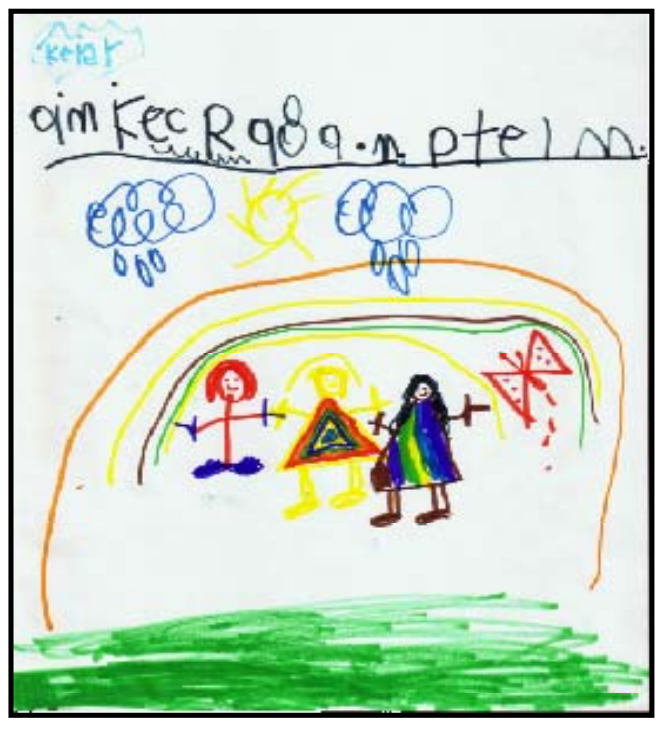
impreso a través de un proceso "natural-emergente" demuestran comprender, desde muy temprana edad, que el lenguaje escrito así como el oral, es un instrumento funcional de comunicación.

Desde esta posición, la labor pedagógica que se desarrolla con niños y niñas del nivel inicial (período de edad entre cero años y seis años), se ha visto enriquecida en los últimos años, con la introducción del ambiente letrado, pues los infantes desde temprana edad tienen la oportunidad de estar en contacto con material impreso, con material para escribir y, lo más importante, con la receptividad del adulto para atender a todas las interrogantes que les planteen, en relación con esta área. 
Por lo tanto, el propósito de este artículo es reflexionar acerca de la función principal del nivel inicial y del proceso de construcción del conocimiento que realiza el niño y la niña en relación con la lectura y la escritura, asimismo dar a conocer algunos aspectos generales de la filosofía del Lenguaje Integral, la cual le brinda un valor fundamental a este proceso y al contexto sociocultural en que se desenvuelven ambos.

A partir de estos elementos, se analizará la organización del ambiente escolar a la luz de estos principios y se propiciarán algunas sugerencias para acercar al niño y a la niña a la utilización del lenguaje escrito y de la lectura, de manera que éstos tenga un acercamiento natural y un proceso exitoso de la apropiación de la escritura y lectura.

\section{La educación inicial: un reto que enfrentar}

La educación inicial en nuestro país ha tenido una evolución trascendental a lo largo de su historia. Primero, ha traspasado las barreras de la simple labor asistencial de las niñas y niños pequeños hasta incorporar el aspecto pedagógico.

Segundo, este nivel ha ampliado su cobertura a una mayor población, lo que le da mayor seguridad a los padres y madres que se integran, cada vez más, a diversas actividades fuera del hogar y que buscan un lugar que les ayude en la educación de sus hijos e hijas desde temprana edad.

Un tercer aspecto que se toma en cuenta en esta valiosa tarea consiste en la formación pedagógica que el niño y la niña deben obtener de acuerdo con sus características y necesidades. De esta manera, el currículo orientado a la educación de los infantes parte de los fines de la educación preescolar propuestos en la Ley Fundamental de Educación de 1957, cuyo artículo doce establece que es misión de este nivel proteger la salud del niño y estimular su crecimiento físico-armónico, fomentar la formación de buenos hábitos, estimular y guiar las experiencias infantiles, cultivar el sentido estético, desarrollar actitudes de compañerismo y cooperación, facilitar la expresión del mundo interior infantil y estimular el desarrollo de la capacidad de observación. Partiendo de estos fines se desprenden los siguientes objetivos, propuestos por el Ministerio de Educación Pública de nuestro país (MEP, 1996): 
1. Propiciar el desarrollo integral de los niños atendiendo las áreas cognoscitivalingüística, socioemocional y psicomotriz, para una mejor calidad de vida como ser individual y social.

2. Favorecer el desarrollo socioemocional del niño, mediante la formación de hábitos para la convivencia social, así como valores y actitudes que le permitan interactuar positivamente con su medio cultural.

3. Promover en el niño el desarrollo de destrezas y habilidades básicas, para el desarrollo óptimo de sus potencialidades.

4. Estimular el desarrollo de la capacidad creadora para enriquecer la libre expresión de la personalidad infantil.

5. Favorecer el desarrollo de actitudes científicas para asumir una posición crítica ante la vida.

6. Promover en los actores sociales una actitud de afecto, respeto y protección para preservar y conservar su ambiente natural, social y cultural.

7. Generar conciencia en los padres y la familia, de su papel en el desarrollo integral de los hijos, para su realización como personas y ciudadanos capaces de asumir la vida responsablemente en una sociedad democrática.

8. Educar para la convivencia social, según los derechos y las libertades fundamentales enunciados en la Declaración de los Derechos del Niño.

Por lo tanto, la tarea principal del nivel inicial se ha dirigido a la expansión del aprendizaje en las tres áreas de desarrollo: socioemocional, psicomotriz y cognitivolingüística, tomando en cuenta las características de desarrollo, su medio sociocultural y la comprensión que cada individuo es único y se desarrolla a su propio ritmo.

A partir de esta premisa, el Ministerio de Educación Pública (1996) hace énfasis en que los niños y niñas de este nivel necesitan de una estimulación apropiada basada en el juego, de una interacción inteligente y creativa por parte del adulto con ellos y viceversa; desechando de sus esquemas la visión escolarizada, para propiciar un proceso formativo permanente, que inicia en la familia y continúa en el preescolar.

Este enfoque sugiere que el nivel inicial se consolide en un currículo integrado, que propicia un proceso de enseñanza dinámico, abierto, flexible y significativo, el cual está centrado en el alumno y el aprendizaje (MEP, 1996). 
De acuerdo con este modelo pedagógico, el docente de preescolar debe asumir el compromiso de permitirle al niño y a la niña construir conceptos y significados a partir de sus experiencias concretas, propiciarles actividades donde el juego se convierta en un medio para el aprendizaje, brindarles espacios para que puedan cuestionarse, plantear sus propias hipótesis, explorar, investigar, tocar, oler, sentir, hablar, y preguntarse acerca de todo lo que pasa a su alrededor. Este nivel es una etapa en la que el niño y la niña deben desarrollar sus capacidades, sus destrezas, sus habilidades, sin perder la oportunidad de seguir siendo niños.

Desde esta posición, el trabajo con preescolares está en manos del docente, quien tiene la responsabilidad de investigar y comprender "cómo la mente y el cuerpo del niño crecen y se desarrollan y cómo éste progresa social, emocional y moralmente, para resolver con inteligencia los problemas infantiles y comprender las causas de su conducta". (Santiago de Palomo, 1997, p. 75)

Por lo tanto, es menester que cada docente conozca cómo es cada uno de sus alumnos y alumnas, qué factores familiares, escolares o de otra índole influyen en él o ella y cómo reaccionan ante ellos, de manera que se forme una imagen de cada estudiante, y pueda, a partir de esta fotografía completa del niño y la niña, buscar las estrategias pedagógicas pertinentes para abordar la labor que realiza. Además, debe conocer también las características individuales de los infantes en cada uno de los niveles, para adaptar favorablemente los contenidos, métodos, técnicas, actividades a la organización del planeamiento y del espacio físico, brindando así, un aprendizaje activo y significativo.

\section{La construcción del conocimiento: una puerta al infinito}

Para favorecer este aprendizaje activo y significativo en el trabajo diario con los niños y niñas del nivel inicial, es importante que el docente tenga una panorámica general de cómo se realiza la construcción de conocimiento en el ser humano.

Es importante, cuando se trabaja con niños y niñas en edad preescolar, tomar en cuenta las experiencias previas que posee, de esta manera el docente puede formarse una idea de la estructura básica de su vocabulario, de su capacidad para expresarse, para resolver un problema y dar respuestas a partir de la experiencia que ha logrado construir en sus primeros años de vida. 
Un aspecto indispensable en la labor pedagógica con los niños y niñas es el ambiente de intercambio que debe promoverse entre estos, y los adultos, ya que según Vigotsky (1964), la interacción entre ellos constituye el origen del aprendizaje y del desarrollo humano. Además, se rescata aquí el concepto de "zona de desarrollo próximo" propuesto por este mismo autor y que se define como el proceso de evolución del estado actual del conocimiento (zona real de desarrollo) hacia un estado superior (zona de desarrollo potencial), que puede darse entre iguales o con un compañero más capaz.

Otro elemento en la construcción del conocimiento es, precisamente, enfrentar al niño y a la niña con retos cognoscitivos, de manera que puedan realizar un proceso de construcción, donde organicen y reorganicen información de acuerdo con sus estructuras mentales y con base en sus experiencias cotidianas. Desde esta perspectiva, la construcción de conocimiento que ambos realizan no se desarrolla a partir de una mente en blanco, sino desde sus conocimientos previos, los cuales sirven para "enganchar" nuevo conocimiento y atribuirle un nuevo significado al conocimiento ya existente (Mauri, 1993).

En relación con la construcción del conocimiento y la escritura, Goodman (1997) expresa que los niños y niñas antes de los cinco años saben mucho acerca del lenguaje escrito, por lo tanto, la escritura se convierte en un objeto de conocimiento, cuyo proceso de construcción es similar al de otros dominios: primero el infante trata de asimilar la información suministrada por el medio ambiente; luego experimenta con las palabras y las letras para tratar de comprender sus propiedades; finalmente prueba hipótesis para tratar de darle sentido al conjunto de datos recogidos.

A partir de este proceso el niño y la niña tratan de sistematizar toda esa información acerca de la lectura y de la escritura; y construyen lo que Ferreiro (1997) citado por Goodman (1997) denomina "teorías infantiles sobre la naturaleza y función del sistema de escritura". Es a través de

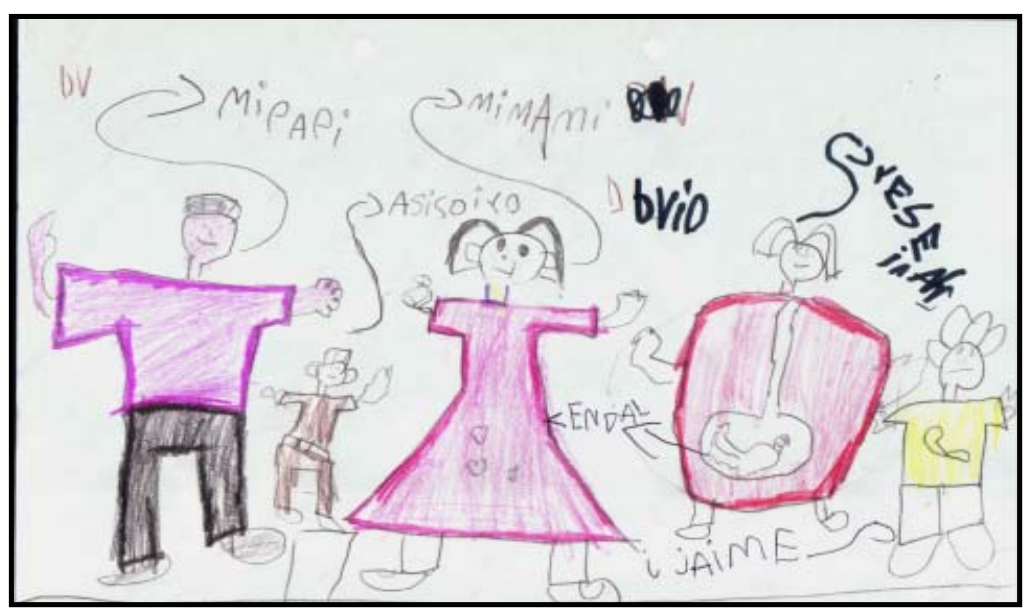

Volumen 6, Número 3, Año 2006, ISSN 1409-4703 
estas teorías que el niño y la niña le dan sentido a su experiencia de escritura, la que se va modificando cada vez que se encuentra con nueva información.

\section{El lenguaje integral: una opción para la construcción del conocimiento}

Una opción para favorecer el aprendizaje significativo lo constituye el Lenguaje Integral, filosofía que responde a una concepción constructivista del proceso educativo, la cual se basa en principios científicos y humanista, y está apoyada por áreas del conocimiento en el campo de la lectoescritura, el desarrollo infantil y el desarrollo curricular integrado. Según Goodman, K, 1970 y Goodman y Goodman, 1993, citados por Chaves, (2002), el Lenguaje Integral no es un método para enseñar a leer y a escribir, sino es una nueva concepción de lenguaje y de ser humano en interacción, donde educadores y educadoras y estudiantes comparten el poder y tienen un papel protagónico en el proceso de enseñanza y de aprendizaje como investigadores de contextos socioculturales para conocer diferentes realidades.

Además, el Lenguaje Integral se nutre de disciplinas como la psicolingüística, la lingüística, la psicología cognitiva y del desarrollo, la antropología y la educación (Arellano, A., 1993). Según Goodman (1989) el Lenguaje Integral involucra la lengua oral y la escrita, e integra el desarrollo de ambas con el aprendizaje a través del currículo.

Algunos de los principios que sustentan esta filosofía se derivan de la Nueva Educación de 1880, de la Educación Progresista de los años 20 con John Dewey, y del movimiento de aula abierta de finales de los años sesenta y comienzos de los años setentas (Arellano, A., 1993).

En los últimos años sus mayores exponentes han sido Kenneth y Yetta Goodman, investigadores estadounidenses que han realizado estudios acerca del desarrollo temprano y el proceso de escritura, de la inteligencia artificial, del análisis del discurso, de la crítica literaria, de la teoría de los esquemas y del análisis de miscues (inventarios de respuestas inesperadas que producen los lectores mientras leen en forma oral)

Seguidamente se indican las bases de la enseñanza integral y los principios en que se sustenta el Lenguaje Integral: 


\subsection{Bases de la enseñanza integral}

Según Goodman (1989, p. 42) "el Lenguaje Integral se apoya en cuatro pilares humanístico-científicos. Tiene una teoría del aprendizaje, una teoría del lenguaje, una visión básica de la docencia y el rol del docente y un concepto del currículo centrado en el lenguaje".

En cuanto a la teoría del aprendizaje se sostiene que aprender el lenguaje es fácil cuando es integral, real y relevante, cuando tiene sentido y es funcional. Asimismo se señala que el lenguaje es tanto personal como social y se aprende a medida que el sujeto lo utiliza para aprender.

Respecto de la teoría del lenguaje se le da valor a todas las lenguas y dialectos, pues se considera que cada forma de lenguaje constituye un recurso lingüístico valioso para sus usuarios, por lo tanto, lo que se pretende es que el Lenguaje Integral sea realmente auténtico.

En relación con la visión de la enseñanza y el rol del docente se plantea que el respeto y la comprensión del aprendizaje y del lenguaje son equivalentes al respeto y la comprensión en la enseñanza. Se apunta que los docentes que aplican la filosofía del Lenguaje Integral se consideran profesionales, en este sentido se mantienen en constante búsqueda del conocimiento, aceptan la responsabilidad de sus éxitos y fracasos, y sienten placer y orgullo por su labor.

Asimismo manifiestan confianza en lo que hacen y en las decisiones que toman, porque conocen las bases humanístico-científicas de su práctica, y en este sentido esperan cierto grado de autonomía en el aula para hacer las adecuaciones pertinentes dependiendo de las características y necesidades de su grupo de alumnos; pues, un maestro integrante entiende que el aprendizaje es un proceso que se desarrolla en los niños y niñas uno a uno, y que su función consiste en crear ambientes e interacciones sociales apropiadas, e influir en la velocidad y dirección del aprendizaje personal, dando guía, apoyo, y facilitando el aprendizaje, pero sin controlarlo.

Por último, en cuanto a la visión del currículo, se sostiene que si el lenguaje se aprende mejor cuando es integral y en un contexto natural, entonces la integración es un 
principio fundamental para el desarrollo lingüístico y el aprendizaje a través del lenguaje. La meta del Lenguaje Integral es el crecimiento individual y no el logro de niveles absolutos. Por lo tanto, hay que aceptar y respetar las diferencias entre los alumnos, ofreciéndoles opciones y dándoles sentido de posesión y relevancia en todo lo que hacen, sólo de esta manera se puede asegurar que el currículo sea lo más efectivo posible.

\subsection{Principios}

El Lenguaje Integral promueve la construcción del conocimiento por parte del niño y la niña, contemplando tanto el aprendizaje del lenguaje como cualquier otro contenido curricular (Arellano, A., 1993). Goodman (1992) plantea que al aplicar el Lenguaje Integral hay que partir de la creencia que hay algo especial en el aprendizaje y en el lenguaje del ser humano, "cada niño tiene un lenguaje y la habilidad para aprenderlo", lo que se debe hacer es invitar al niño y a la niña a aprender a leer leyendo y a escribir escribiendo partiendo de sus propias producciones. Según Goodman (1989) los principios de esta filosofía se clasifican en dos grupos:

1. Principios para la lectura y la escritura: el lector construye significados durante la lectura; predice, selecciona, confirma hipótesis y se autocorrige a medida que intenta encontrarle sentido a la palabra impresa. La meta del lector es la comprensión de significados y la del escritor es la expresión de significados, en este sentido ambos están limitados por lo que saben.

2. Principios para la enseñanza y el aprendizaje: los programas escolares de lectoescritura deben construirse sobre el aprendizaje existente y las motivaciones intrínsecas del alumno; este proceso de lectura y de escritura evoluciona del todo a la parte; no existe una jerarquía en el aprendizaje. El aprendizaje integral del lenguaje se forma con aprendices integrales, aprendiendo en situaciones integrales.

Partiendo de esta rápida caracterización, un docente que verdaderamente desee promover un proceso acorde con las características y necesidades de los niños y niñas del nivel inicial y favorecer el desarrollo de todo su ser, debe tomar algunos elementos en cuenta al trabajar bajo esta filosofía:

1. El ambiente que se genera en un salón de clase es un factor importante a considerar, desde la perspectiva del Lenguaje Integral el espacio del aula puede dividirse en áreas de trabajo como las siguientes: dramatización, construcción, juegos tranquilos, artes 
plásticas y el centro de lenguaje. De acuerdo con el tamaño del aula se pueden incluir otras áreas como investigación científica, investigación social, agua, arena y carpintería.

2. Con respecto de la decoración del aula, se señala que desde la perspectiva del Lenguaje Integral es fundamental un ambiente letrado.

3. Utilizar los trabajos que los niños y niñas realizan en clase o en el hogar para decorar las paredes, pegándolos a su altura y variándolos de acuerdo con el tema en estudio y sus intereses. En este sentido, es importante darle la oportunidad a los pequeños de que ellos decoren el aula construyendo un ambiente con el tema que eligieron trabajar.

4. Los materiales y recursos que posee un aula bajo la filosofía del Lenguaje Integral debe invitar al niño y a la niña a elegir, explorar, experimentar, clasificar, probar, compartir, interactuar, leer y escribir, así como también favorecer la independencia, la autonomía, la responsabilidad, el autocontrol, la cooperación, la concentración, el trabajo en equipo y la organización.

\section{La lectura y la escritura: una alternativa para conocer el mundo}

Según Vigotsky (1978, p. 118), el mejor método para enseñar a leer y escribir es aquel en el que los niños no aprenden a leer y escribir sino en el que ambas cosas se encuentran en una situación lúdica... De la misma forma en que los niños aprenden a hablar, deberían aprender a leer y escribir.

Partiendo de esta idea, se considera oportuno presentar en este apartado, algunas categorizaciones que realizan los autores en relación con el proceso de lectura y escritura que realiza el niño y la niña.

Goodman (1980), señala en cuanto a la lectura que los niños y niñas primero desarrollan una conciencia de las palabras escritas en su entorno social, aproximadamente entre los dos y los cuatros años de edad estos realizan su primera construcción clave, las palabras escritas comunican mensajes. De esta manera, los infantes comienzan a leer los símbolos escritos de los mensajes que les son significativos o familiares, por ejemplo el niño o la niña cuando viajan con sus padres pueden señalar las 
palabras Mc Donald's o Coca cola de los letreros o señalar la palabra leche de una caja que su madre compró en el supermercado. Esta misma autora comenta que en esta etapa los pequeños preguntan mucho acerca del significado de las palabras.

Posteriormente extienden este conocimiento hacia las palabras escritas en los libros, y empiezan a comprender que el lenguaje escrito y el oral tienen la función de comunicar, este conocimiento lo adquieren al manipular libros, cuentos, revistas, al observar a su familia leer el periódico y escuchar que el lenguaje escrito se lee oralmente. Una característica de los niños y niñas a esta edad es tomar un libro, abrirlo, pasar las páginas y leer imitando al adulto.

Más adelante se dan cuenta de que son las palabras las que expresan, fundamentalmente un mensaje, este conocimiento adquirido por el niño y la niña según Goodman (1980) parece ser un factor muy importante en el desarrollo de la alfabetización. Esto sucede cuando los infantes tienen entre cuatro y seis años de edad.

Desde esta perspectiva, el adulto que lea con el niño o la niña desde temprana edad, le ayudará en su proceso de construcción de significados, principalmente porque el infante desde pequeño siente gran placer por la literatura y constantemente solicita al adulto, le lea un cuento una y otra vez hasta que es capaz de "leer" la historia por sí mismo. Durante esta repetición el infante pasa por un proceso en el que va memorizando el contenido de la historia y poco a poco le va prestando atención a los rasgos particulares de las palabras y letras, para abstraer las normas particulares de la escritura.

Se presenta a continuación los niveles conceptuales de la alfabetización temprana, apoyándose en la propuesta de Ruiz (1996, pp.16-17) en su libro La alfabetización temprana en el ambiente preescolar. 


\begin{tabular}{|c|c|c|}
\hline $\begin{array}{l}\text { Clasificación } \\
\text { de los nivel }\end{array}$ & $\begin{array}{c}\text { Edad } \\
\text { aproximada }\end{array}$ & Características del nivel \\
\hline $\begin{array}{c}\text { Nivel I } \\
\text { Concientización } \\
\text { del lenguaje } \\
\text { impreso en el } \\
\text { entorno social }\end{array}$ & 2 a 4 años & $\begin{array}{l}\text { 1. El niño se percata en este nivel que el lenguaje } \\
\text { escrito en su medio ambiente comunica un } \\
\text { mensaje. } \\
\text { 2. Comienza la "lectura" de palabras en contexto } \\
\text { (rótulos, etiquetas, nombres de comercios, entre } \\
\text { otros). }\end{array}$ \\
\hline $\begin{array}{c}\text { Nivel II } \\
\text { Concientización } \\
\text { del lenguaje } \\
\text { escrito en libros }\end{array}$ & 3 a 5 años & $\begin{array}{l}\text { 1. El niño descubre que el lenguaje escrito en los } \\
\text { libros suena diferente al lenguaje oral. Observa } \\
\text { que el cuento tiene un principio, desarrollo y final. } \\
\text { 2. Además, desarrolla relaciones espaciales en los } \\
\text { libros (arriba, abajo, al frente, atrás, etc. )al igual } \\
\text { que otras habilidades para manejarlo } \\
\text { adecuadamente. } \\
\text { 3. El niño imita el comportamiento del adulto al leer, } \\
\text { pasando las páginas correctamente. }\end{array}$ \\
\hline $\begin{array}{c}\text { Nivel III } \\
\text { Inicio de la } \\
\text { lectura de libros }\end{array}$ & 3 a 6 años & $\begin{array}{l}\text { 1. El niño lee el cuento usando las láminas como } \\
\text { claves, lee el cuento parafraseando. } \\
\text { 2. A esta edad el niño se percata que las palabras } \\
\text { escritas en el libro dicen el cuento y no las } \\
\text { imágenes. } \\
\text { 3. Puede señalar al leer el texto de izquierda a } \\
\text { derecha, si ha visto hacerlo al adulto. } \\
\text { 4. Parafrasea integrando palabras y frases del texto. } \\
\text { 5. Memoriza el cuento y lo lee palabra por palabra. } \\
\text { 6. Puede parear algunas palabras del texto con lo } \\
\text { que dice. } \\
\text { 7. Abstrae las normas del lenguaje escrito al utilizar } \\
\text { claves semánticas, sintácticas y fonéticas para } \\
\text { confirmar las predicciones de su lectura. } \\
\text { 8. Al final de este nivel el niño es capaz de leer } \\
\text { convencionalmente al integrar su conocimiento } \\
\text { sobre el lenguaje oral con el lenguaje escrito. }\end{array}$ \\
\hline
\end{tabular}

En relación con el desarrollo de la escritura Harste et al, (1982) citado por Ruiz (1996), señala que debido a la gran exposición que tienen los niños y niñas desde edades muy cortas con el lenguaje impreso, éstos desarrollan unas expectativas funcionales de las letras, así como un conocimiento acerca de la relación entre grafemas (letras) y fonemas (sonidos) antes de la instrucción formal de la lectura. Sin embargo, el niño en sus inicios al solicitársele que escriba, sustituye las letras por garabatos o dibujos, ya que de alguna manera este se convierte en un medio de comunicación escrito.

*transformación de los símbolos escritos en mensajes significativos 
De igual manera se indican a continuación los niveles conceptuales de la escritura emergente, apoyándose en la propuesta de Ruiz (1996, p. 19-33) en su libro La alfabetización temprana en el ambiente preescolar.

1. Garabatos: representan el primer intento del escritor incipiente para comunicarse mediante la escritura. Estos garabatos expresan un mensaje y pueden ser comprendidos únicamente por el infante. Este proceso se contempla desde garabatos desordenados (trazos sin significado conceptual) a la representación de garabatos organizados

(trazos controlados a los que se les atribuye significado conceptual y lingüístico), que tienen cierta similitud

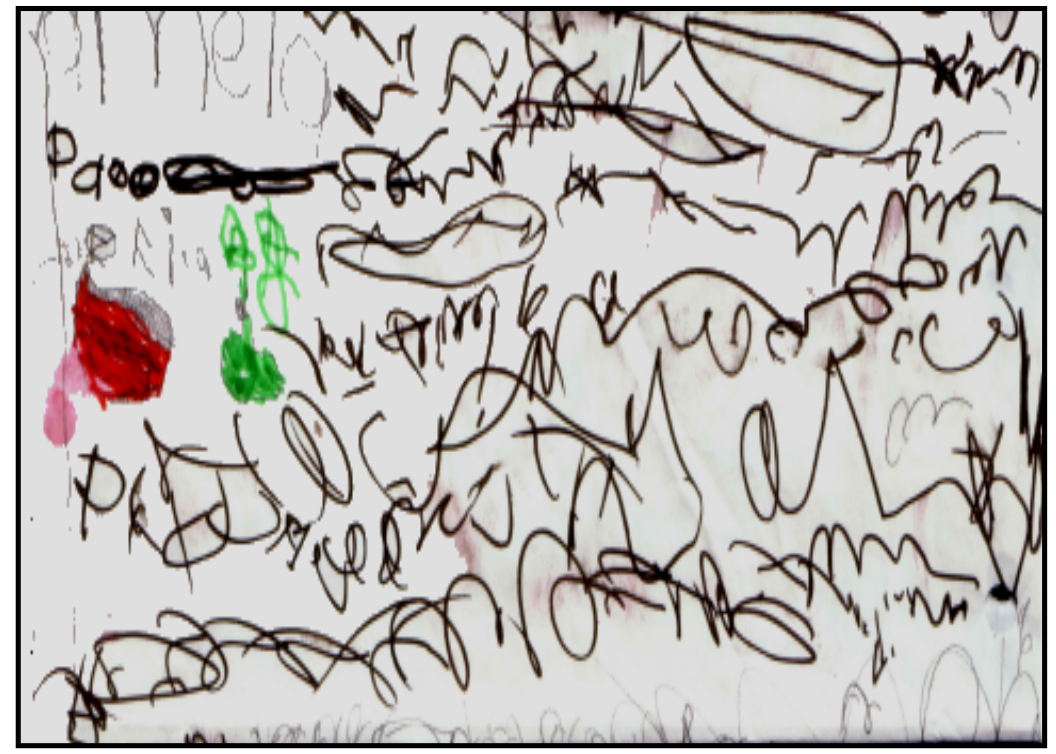
con la escritura cursiva del adulto.

2. Escritura telegráfica: escritura que el niño o la niña emplea para comunicar mensajes extensos mediante una o varias letras o numerales esporádicos. En algunas ocasiones el niño dibuja cuando se le solicita que escriba, pues aún no existe una clara diferenciación entre ambos procesos. En esta etapa sólo el niño puede comprender los mensajes escritos.

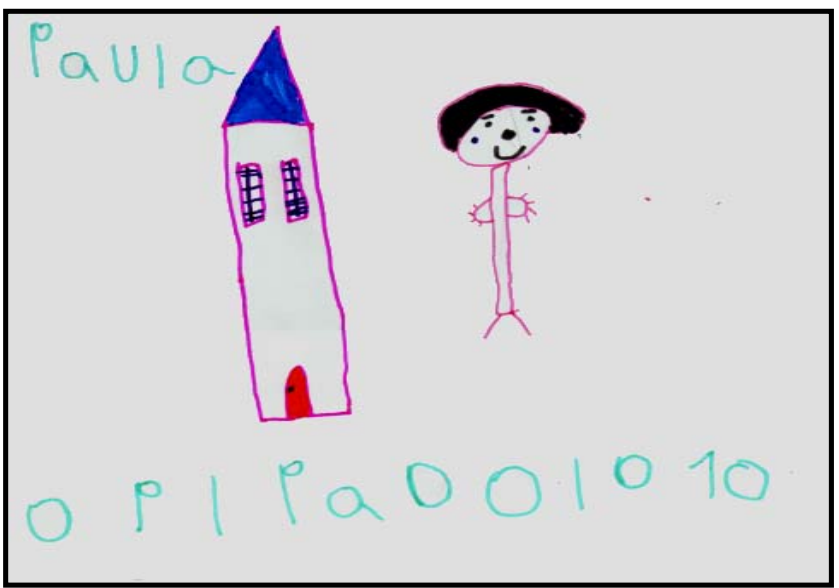


3. Escritura prealfabética temprana: el niño y la niña realizan hileras de letras en posición horizontal, siguiendo el patrón direccional de la escritura del adulto. Aún el adulto no puede comprender lo que escribieron, en alguna medida pareciera que el niño y la niña retrocede en este proceso pues pueden indicar que no saben leer, sin embargo, lo que realmente ocurre es que ambos comienzan a percatarse de que existen unas reglas particulares, para comunicarse mediante el

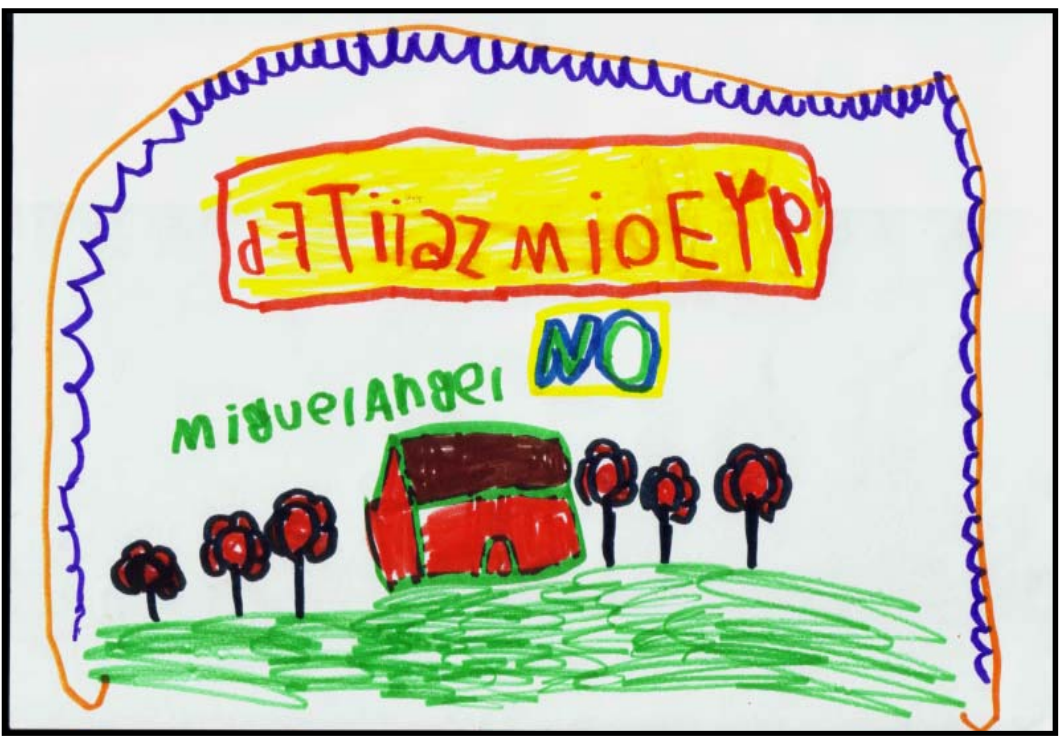
lenguaje escrito.

4. Escritura prealfabética: escritura de una letra o símbolo para representar sílabas o partes de palabras, de acuerdo con lo que el niño o niña escuchan al pronunciarlas. En esta etapa aún es indispensable la lectura del infante para la completa comprensión por parte del adulto.

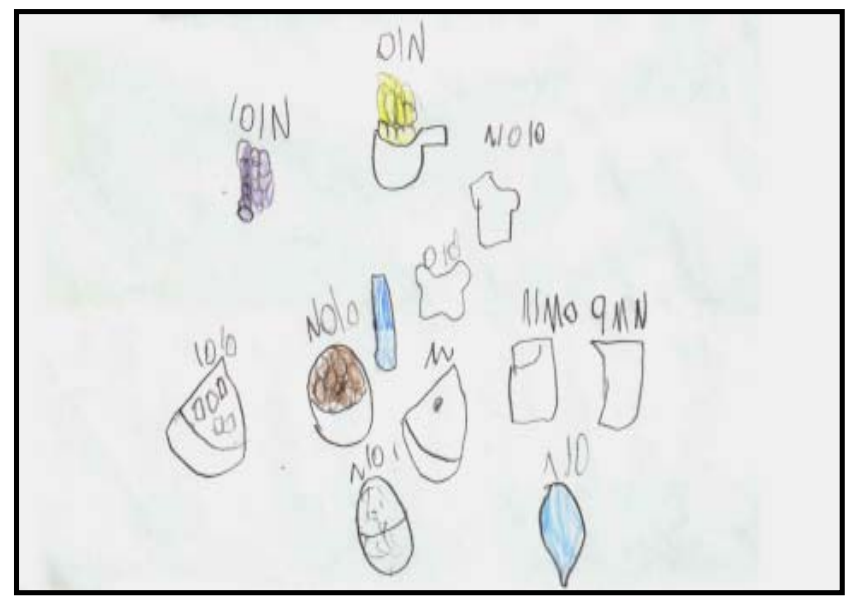

5. Escritura alfabética: el niño y la niña demuestran conocer el principio de correspondencia entre grafemas y fonemas, al incluir todas las letras necesarias para las palabras que escribe, generalmente no las separa, sin embargo, el mensaje que escribe es comprensible por parte del adulto. 


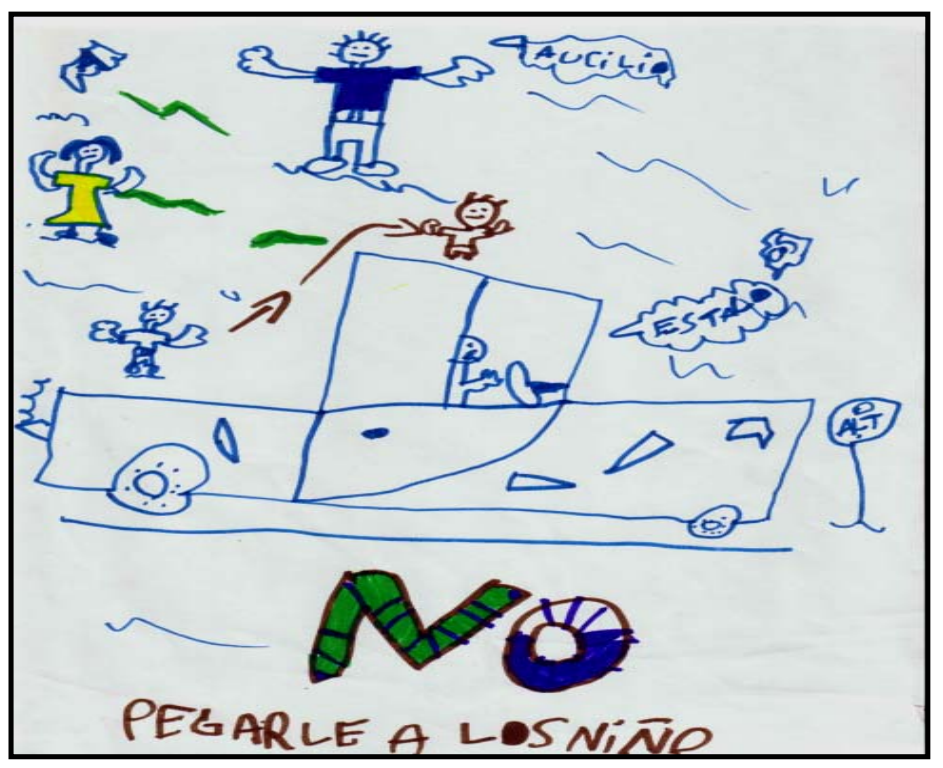

6. Escritura convencional: se refiere a la escritura de palabras ortográficamente correctas.

Ferreiro, 1986 y Ferreiro y Teberosky, 1982 citadas por Goodman (1997, p. 24-32) distinguen tres niveles en el desarrollo de la alfabetización, que pueden servir de complemente a la propuesta de Ruiz.

\section{Primer nivel:}

En este nivel los niños y niñas tratan de buscar criterios para distinguir el dibujo y la escritura, desde esta construcción reconocen dos características básicas: las letras no reproducen las formas de los objetos y están ordenadas de modo lineal a diferencia de los dibujos. A partir de este descubrimiento los niños y niñas inician otro proceso de distinción que corresponde a la relación dibujo - escritura, del cual llegan a concluir, que las letras se usan para representar una propiedad de los objetos, es decir sus nombres, dado que el dibujo no tiene esa capacidad.

A partir de este proceso los infantes empiezan a cuestionarse de qué manera las letras se organizan para representar adecuadamente los nombres y cuántas letras tiene que poseer una palabra para que sea "legible", de igual manera empiezan a realizar letras diferentes pues no consideran que una cadena de letras sea legible si es igual. 


\section{Segundo nivel:}

En este nivel los niños y las niñas tratan de buscar diferencias gráficas, que puedan sustentar sus diferentes intenciones. Es decir, ahora el pequeño conoce que dos hileras de letras idénticas no pueden decir dos cosas diferentes. En este nivel la cantidad mínima y las variaciones en las hileras de las letras se mantiene igual que el nivel anterior, sólo que se desarrolla un proceso de comparación de carácter interrelacional entre los diferentes nombres escritos.

\section{Tercer nivel:}

Este nivel corresponde a la "fonetización" que se caracteriza por tres hipótesis: la silábica, la silábica - alfabética y la alfabética.

La hipótesis silábica le permite al niño y a la niña un control cuantitativo sobre sus producciones, estos ponen tantas letras como sílabas, en otros casos los niños y niñas utilizan letras específicas para representar una sílaba determinada, por ejemplo la $\mathbf{N}$ de Natalia es Na. Desde este punto de vista, empiezan a buscar letras similares para escribir segmentos de sonidos similares en las palabras.

En la hipótesis silábico - alfabética, algunas letras todavía ocupan el lugar de las sílabas y otras el lugar de las unidades sonoras menores. (fonemas).

La hipótesis alfabética contempla la construcción que hace el niño y la niña de la escritura al comprender que la similitud sonora implica similitud escrita y, que las diferencias sonoras suponen letras diferentes. En este proceso ambos han entendido la naturaleza del sistema alfabético pero aún le quedan muchos aspectos que mejorar, por ejemplo la ortografía.

El desglose de los procesos de lectura y de escritura, presentados en este apartado tienen el propósito de ayudarle al docente del nivel inicial que trabaja con lineamientos del lenguaje integral, a entender el proceso de lectoescritura que va construyendo el niño y la niña desde temprana edad, así mismo concientizarle que su función como mediador o mediadora pedagógica, debe orientarse a la comprensión de que todos sus alumnos son capaces de leer y escribir, pero que cada uno de ellos puede encontrase en diferentes niveles de conceptualización, los cuales debe estimular y atender en sus momentos cruciales de desarrollo.

No obstante, es importante considerar en esta sección que la escritura no significa que el niño o la niña pierda la oportunidad de divertirse y aprender por medio del juego, ni que la utilización de un ambiente letrado en el salón de clases del nivel inicial se transforme en un 
sistema rígido y escolarizado. Al contrario el empleo de la escritura puede utilizarse para incrementar y ampliar actividades como el juego, el dibujo, la expresión oral y las relaciones sociales, descubriéndose, tal y como lo señala McLane citado por Moll (1993, p. 354) que la escritura le ofrece "un instrumento nuevo y provocativo para interactuar con las personas que los rodean y para establecer relaciones más interesantes que las que de otro modo establecerían".

Esta construcción que el niño y la niña hacen acerca del lenguaje desde edad temprana, les permite ver la lectura y la escritura como un proceso emergente que parte de múltiples interpretaciones, hasta que logra realizar una construcción auténtica, al responderse paulatinamente cada una de sus interrogantes. Esta situación, según lo indican Goodman y Goodman citados por Moll (1993) le permiten al niño a la niña entender que el lenguaje es la puerta para la construcción del aprendizaje, y no un instrumento misterioso empleado por los adultos.

\section{Juguemos a leer y escribir}

A partir de los planteamientos desarrollados en este documento se indican a continuación una serie de sugerencias que una docente o un docente del nivel inicial puede poner en práctica en su salón de clases, para acercar al niño y a la niña a la lectura y escritura de manera natural.

1. Es importante que el docente tenga presente que al trabajar bajo las condiciones de un ambiente letrado, se estimule la exploración del lenguaje por medio de experiencias lúdicas, significativas y pertinentes al contexto en el que se desenvuelve el niño y la niña.

2. Es recomendable que al utilizar el lenguaje gráfico con los niños y niñas, este no se convierta en un fin en sí mismo y se saturen las experiencias diarias con actividades exclusivas de esta índole, por el contrario pueden alternarse actividades donde sea el docente quien escriba en conjunto con los niños, o puede que en un día completo no se haga uso de él.

3. Un ambiente letrado debe construirse a partir del interés de los infantes, en este sentido la rotulación del ambiente, de los objetos, juguetes u otros materiales debe hacerse a partir de la iniciativa de éste. En algunas ocasiones puede ser el niño o la niña quien 
escriba el nombre del objeto desde su punto de vista o ser el docente quien asuma esta tarea.

4. Es importante motivar al niño y a la niña para que escriba, para que se exprese en forma gráfica, para que imagine las palabras y poco a poco le vaya perdiendo el miedo, situación que es evidente cuando tienen poca estimulación en su hogar.

5. Dependiendo de la edad del niño o niña el docente debe tomar en cuenta el tiempo y el lugar que se determina para la realización de actividades de lectoescritura, de manera que los educandos tengan la oportunidad de realizar un trabajo con calma y de acuerdo con su propio ritmo.

6. Se recomienda transformar la tradicional área de literatura por el área de lenguaje incorporando material letrado, ésta debe organizarse de manera que resulte muy atractiva para el niño y la niña. En ella pueden ubicarse materiales como los siguientes:

- tarjetas de dibujo - palabra de objetos del ambiente o de animales

- tarjetas de vocabulario de temáticas que el niño esté desarrollando en el aula

- cuentos con su correspondiente historia para trabajar en el franelógrafo

- cuentos de rodillo o rollos con vocabulario

- libros de cuentos, de fábulas, de información, de rimas, de poesías, de autores nacionales, periódicos, panfletos médicos, de nutrición, de turismo, entre otros. Además pueden contemplarse la introducción de los libros, boletines u otros materiales realizados por los mismos niños. Es recomendable cambiar este material regularmente cada tres o cuatro semanas según el interés que mantenga el estudiante

- es imprescindible que en el área exista una grabadora y casetes con cuentos auditivos, cuentos grabados en los que se debe seguir su narración con el apoyo de un libro, casetes con canciones, rimas y en blanco para ser utilizados por los niños o en su equivalentes de CD

- se pueden ubicar en esta área carteles, pancartas, afiches elaborados por los mismos pequeños

- implementar este espacio con juegos como bingos con el dibujo y la palabra, memorias, juegos de asociación dibujo palabra, rimas de ensamble en el que se paree el dibujo con la rima o poesía. 
- incorporar juegos de letras para que el niño y la niña construyan palabras confeccionadas con diversos materiales por ejemplo lija, cartón, espuma, fieltro, plástico, madera, entre otros; de tal manera, que estimule a su vez las diversas sensaciones

- una máquina de escribir o una computadora sería una gran atracción y ayuda en este lugar

- de igual manera es imprescindible todo tipo de material que permita la construcción de textos por parte del niño y la niña, por ejemplo: pliegos grandes de papel, papel de diversos tamaños y colores, lápices de grafito, crayolas, lápices de color, marcadores, goma, tijeras, tizas, pizarra, entre otros materiales que inviten a escribir

- puede incluirse en este lugar las pizarras de arena o harina para que el niño escriba utilizando sus dedos

7. Otra de las sugerencias que puede ayudar a favorecer el ambiente letrado con los niños y niñas se relaciona con la incorporación del buzón de correspondencia en el aula, el cual puede ubicarse afuera de ésta para que exista comunicación entre familia e infantes o entre los niños y niñas y el resto del personal de la institución. Una modificación de esta propuesta consiste en confeccionar con los niños su propio sobre grande de correspondencia de manera que quien escriba una carta o nota a un compañero la deposite en el sobre de éste.

8. Se puede confeccionar un pasalista con el nombre de los niños y niñas, sin ningún otro distractor, de manera que esté siempre a disposición de los niños para que éstos los utilicen cuando lo crean oportuno.

9. Incorporar en el planeamiento diario y en las actividades que se desarrollan cotidianamente espacios en los que el niño y la niña tengan la oportunidad de escribir ( $a$ su manera) su nombre en los trabajos que realiza, escribir acerca de lo que dibuja o hace, escribir cuentos, escribir cartas, escribir poesía, experiencias, etc.

Las sugerencias anteriores son sólo algunas ideas a partir de las cuales un docente puede crear otras y adaptarla a la realidad escolar y social de cada uno de sus alumnos. 


\section{Reflexión final}

Iniciar un proceso en el cual se favorezca un enfoque para el desarrollo de la lectura y escritura de forma natural, no es fácil, por lo tanto el docente o la docente que desee iniciar una tarea de esta magnitud debe partir de una profunda reflexión, del conocimiento que brinda la teoría y de la receptividad hacia el trabajo que el niño y la niña realiza, de manera que se convierta en un mediador, y oriente al infante en su proceso de construcción del lenguaje.

De igual manera, este proceso natural - emergente de la lectoescritura, le ofrece grandes beneficios al niño y a la niña, puesto que favorece la apropiación de la lectura y de la escritura, contribuye al desarrollo de la socialización; ya que éste proceso de escritura y de lectura es netamente social.

Una adecuada implementación de un ambiente letrado, debe desarrollarse paralelo a un proceso de estudio y reflexión en torno a la teoría del Lenguaje Integral, de manera que el proceso de escribir y de leer, pueda desarrollarse tomando en cuenta las características de desarrollo de los niños y niñas, y las diversas disciplinas o áreas del currículo preescolar.

Por último, es importante recordar que el niño y la niña del nivel inicial aprenden por medio de experiencias concretas y por medio del juego, por lo tanto la utilización de un ambiente letrado en el salón de clases, debe emplearse de manera espontánea, invitando al niño y a la niña a acercarse a el, por curiosidad o por placer. 


\section{REFERENCIAS}

Arellano- Osuna, Adelina. (1990). Avances de la lectura y la escritura en la escuela básica. Recuperado el 11 de octubre de 2006, de http://iacd.oas.org/interamer/Interamerhtml/Rodr39html/Rod39 Arell.htm

Arellano- Osuna, Adelina. (1993). El lenguaje integral: una alternativa para la educación. Mérida, Venezuela: Editorial Venezolana C.A.

Chaves, Lupita. (2002). Develando la acción pedagógica en un salón de clase de educación inicia. Recuperado el 11 de octubre de 2006, de http://revista.inie.ucr.ac.cr/articulos/2-2002/archivos/develando.pdf

Coll, César; Martín, Elena; Mauri, Teresa ; Onrubia, Javier ; Solé, Isabel; \& Zabala, Antoni. (1997). El constructivismo en el aula. Barcelona, España: Editorial GRAÓ.

Goodman, K.enneth (1989). Lenguaje integral. Mérica, Venezuela: Editorial Venezolana C.A.

Goodman, Yetta., Altwerger, Bess. (1981). A study of the development of literacy in preschool children. Occasional Papers, Program in Language and Literacy, Tucson, University of Arizona College of Education.

Goodman, Yetta. (1980). The roots of literacy. Paper presented at the annual meeting of the Claremont Reading Conference, Claremont, C.A.

Goodman, Yetta. (1997). Los niños construyen su lectoescritura. Un enfoque Piagetiano. Cuarta edición. Argentina: AIQUE

Kaufman, Ana., Castedo, Mirta. (1990). Alfabetización de niños: construcción e intercambio. Experiencias pedagógicas en jardín de infantes y escuela primaria. Tercera edición. Argentina: AIQUE.

Mauri, Teresa. (1993). ¿Qué hace que el alumno y la alumna aprendan los contenidos escolares?. En El constructivismo en el aula (pp. 71). Barcelona: GRAÓ

Ministerio de Educación Pública. (1996). Programa de estudios, educación Preescolar: Ciclo de Transición. San José, Costa Rica: El Ministerio

Moll, Luis. (1993). Vygotsky y la educación. Connotaciones y aplicaciones de la psicología sociohistórica en la educación (2a. ed.) Argentina: AIQUE.

Ruiz, Daisy. (1996). La alfabetización temprana en el ambiente preescolar. Nuevas perspectivas para aprender a leer y escribir. Puerto Rico

Santiago de Palomo, J., Martínez de Pérez, N. \& Repetto de Braga, C. (1997). La transformación educativa en el nivel inicial. Buenos Aires, Argentina: Editorial Magisterio del Río de la Plata.

Vigotsky, Lev. (1964). Pensamiento y lenguaje. Teoría del desarrollo cultural de las funciones psíquicas. Traducción de María Margarita Rotger. Argentina: Editorial Lautaro. 